\title{
Restriction Fragment Polymorphism in Mitochondrial DNA of Cryptococcus neoformans
}

\author{
By ASHOK VARMA* AND K. J. KWON-CHUNG \\ Laboratory of Clinical Investigation, National Institute of Allergy and Infectious Diseases, \\ National Institutes of Health, Bethesda, Maryland 20892, USA
}

(Received 18 April 1989; revised 16 June 1989; accepted 10 August 1989)

\begin{abstract}
The restriction patterns of mitochondrial DNA from 20 isolates of the two varieties of Cryptococcus neoformans were compared. The patterns exhibited extensive heterogeneity among the isolates regardless of their serotype or varietal status. Hybridizations with cloned fragments of the conserved cytochrome oxidase gene from Saccharomyces cerevisiae exhibited at least seven patterns among the 20 isolates. There were, however, similarities in the restriction patterns among isolates within the same serotype that were not shared by isolates of other serotypes. Intra-varietal similarities were observed in the restriction patterns among the isolates of $C$. neoformans var. neoformans which were not present in the restriction patterns among the isolates of $C$. neoformans var. gattii. Hybridization of some cloned mitochondrial DNA fragments to total DNA digests of various isolates revealed polymorphic as well as variety-specific patterns of homology. These findings agree with the antigenic heterogeneity among the isolates and support the current taxonomic classification of $C$. neoformans into two varieties.
\end{abstract}

\section{INTRODUCTION}

Traditional approaches to the study of genetic relatedness among species have involved the use of such techniques as DNA-DNA hybridization, DNA sequence analysis, protein sequence comparisons, electrophoretic variations in proteins, and protein immunology. The increasing use of endonuclease restriction pattern analysis of mitochondrial DNA (mtDNA) as a sensitive indicator of genetic relatednesss or divergence within a taxonomic group reflects the significance of the approach (Fox, 1979). Although the mitochondrial genome is functionally conserved in all metazoan animals (Gray, 1982), its small size, relative ease of isolation, and particularly its ability to sustain an unusually high degree of primary sequence divergence (via base substitutions, deletions, sequence insertions, etc.) makes it an appropriate choice for such a study. Cryptococcus neoformans, a sexually dimorphic yeast-like fungal pathogen, has been classified into two varieties, $C$. neoformans var. neoformans and $C$. neoformans var. gattii (KwonChung, 1983). Hybridization studies with total DNA showed the two varieties to share $55-63 \%$ DNA homology (Aulakh et al., 1981). Within each variety, antigenic heterogeneity has been recognized: $C$. neoformans var. neoformans includes isolates of serotypes $\mathrm{A}$ and $\mathrm{D}$, while the variety gattii includes isolates of serotypes $\mathbf{B}$ and $\mathrm{C}$. The major environmental source for $C$. neoformans var. neoformans is pigeon droppings (Kwon-Chung \& Bennett, 1984), but the ecological niche of the variety gattii, is still unknown. Epidemiological studies have shown isolates of $C$. neoformans var. neoformans to be frequent causes of infection world-wide, whereas isolates of the variety gattii are infrequent causes of infection except in tropical and sub-tropical regions (Kwon-Chung \& Bennett, 1984). In spite of the increasing number of published reports on the similarities and differences between the two varieties, there is a noticeable lack of studies concerning the genetic diversity of isolates within and among the serotypes and/or varieties.

Abbreviation: mtDNA, mitochondrial DNA. 
Recently, Polacheck \& Lebens (1989) showed that extensive polymorphism exists among isolates of the two varieties in their electrophoretic karyotype.

In this study we compared the restriction patterns of mtDNA from 20 isolates of the two varieties of $C$. neoformans. In contrast to studies on other pathogenic fungi such as Candida albicans (Willis et al., 1985) and Histoplasma capsulatum (Vincent et al., 1986), we observed extensive polymorphism in the mtDNA restriction patterns among the isolates of $C$. neoformans. We also cloned mtDNA fragments into Escherichia coli vectors and used them as probes against total DNA from various isolates of the four serotypes. Some of these clones may be useful tools in determining the varietal status of atypical isolates that give ambiguous results by conventional methods.

\section{METHODS}

Strains and vectors. Sources of the Cryptococcus neoformans isolates used in this study are listed in Table 1. These 20 isolates were confirmed as $C$. neoformans and, based on their reaction to CGB medium, were further classified as either of the variety gattii or of the variety neoformans (Kwon-Chung et al., 1982). The serotype of each isolate was determined as described by Wilson et al. (1968). Escherichia coli JM83 (a restriction-minus strain) was kindly provided by Jeff Ostrove (NIH, Bethesda, Md, USA). E. coli host strain DH5 $\alpha$ and cloning vector pUC8 were obtained from Bethesda Research Laboratories (BRL). YEp plasmids containing the BamHI-HindIII fragment (DS6422/STB) and the HindIII-EcoRI fragment (DS6422/STA) of the cytochrome oxidase (subunit one) gene from Saccharomyces cerevisiae were kindly provided by A. Tzagoloff (Columbia University, NY, USA). All isolates of $C$. neoformans were maintained on slants of YEPD agar $(1 \%, w / v$, yeast extract, $2 \%$, w/v, peptone, and $2 \%, w / v$, glucose).

Isolation of mtDNA. A modification of the procedure previously used in Saccharomyces cerevisiae (Hudspeth $e t$ $a l ., 1980$ ) was applied. Yeast cells from isolates of each serotype were grown in 2-litre broth cultures containing $1 \%$

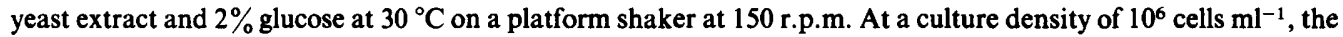
cells were harvested by centrifugation, washed in $1 \mathrm{M}$-sorbitol, then resuspended in protoplasting solution (Rhodes \& K won-Chung, 1985) containing $1 \mathrm{M}$-sorbitol, $100 \mathrm{~mm}$-2-mercaptoethanol and Novozyme 234 (Novo Industries, Denmark) $\left(1 \mathrm{mg} \mathrm{ml}^{-1}\right)$. After incubation at $30^{\circ} \mathrm{C}$ for $15-30 \mathrm{~min}$, protoplast formation was determined by phasecontrast microscopy of a drop of cell suspension before and after the addition of a drop of $20 \%(\mathrm{w} / \mathrm{v})$ SDS solution (Fisher Scientific). When greater than $90 \%$ lysis occurred, the protoplasts were harvested by centrifugation at 5000 r.p.m. for $5 \mathrm{~min}$ and resuspended in $0.05 \mathrm{M}$-Tris/EDTA. The protoplasts were then lysed by the addition of SDS to a final concentration of $2 \%$. The mixture was placed in an ice bath for $20 \mathrm{~min}$ to complete lysis and subsequently centrifuged at 15000 r.p.m. in an SS34 rotor (Dupont Instruments) for 30 min to remove cellular debris. After transfer to a clean tube, $1.1 \mathrm{~g}$ solid $\mathrm{CsCl}$ per $\mathrm{ml}$ of lysate was added to the clear supernatant. Bulk protein was removed as a top pad after centrifugation at 16000 r.p.m. in a Sorvall SS34 rotor. Bisbenzimide (Sigma) was added to a final concentration of $100 \mu \mathrm{g} \mathrm{ml}^{-1}$ and the refractive index adjusted to $1 \cdot 397$. Following centrifugation for 18$20 \mathrm{~h}$ at 54000 r.p.m. in a VTi 65.2 rotor (Beckman Instruments) at $17^{\circ} \mathrm{C}$, the upper fluorescent band (Fig. 1) was removed under long-wave ultraviolet illumination. For cultures exceeding 2 litres, it was found convenient to deproteinize the lysates with phenol/chloroform, precipitate the DNA from $0.5 \mathrm{M}$-ammonium acetate with 2 vols ethanol and resuspend the DNA in $5 \mathrm{ml} 10 \mathrm{~mm}-\mathrm{Tris} / \mathrm{HCl}(\mathrm{pH} \mathrm{7.4)}$ plus 1 mM-EDTA. This concentration step facilitated the extraction of DNA from large culture columes into a single gradient tube and eliminated the need to deproteinize by centrifugation prior to bisbenzimide addition. The dye was extracted from the mtDNA in 2propanol saturated with $\mathrm{CsCl}$ (Williamson \& Fennell, 1975). The mtDNA was then purified by diluting in 3 vols water followed by ethanol precipitation.

Endonuclease restriction and electrophoresis. Restriction endonucleases were obtained from BRL and the reactions carried out according to the supplier's directions. Electrophoresis was performed in $0.8 \%$ agarose (BRL) gels and the restriction fragments were visualized by ultraviolet fluorescence after staining with ethidium bromide (Sigma). Bacteriophage $\lambda$ DNA fragments (BRL) digested with HindIII, and the $1 \mathrm{~kb}$ ladder, were used as size references.

Cloning of mtDNA fragments. mtDNA from a representative isolate of each serotype (NIH-68, NIH-444, NIH191 and B-3501), and the vector pUC8, were digested with SalI at $37^{\circ} \mathrm{C}$. mtDNA from isolate NIH-68 was similarly digested with $\mathrm{XbaI}$. The resulting fragments were ligated into the respective cloning site of the $E$. coli vector pUC8 at $15^{\circ} \mathrm{C}$ for $2-4 \mathrm{~h}$ in the presence of T4 ligase and reaction buffer provided by BRL. The ligation mixtures were used to transform the competent $E$. coli strain DH5 $\alpha$. The insert-containing transformants were identified as white colonies on $\mathrm{LB}$ plates supplemented with ampicillin $\left(40 \mu \mathrm{g} \mathrm{ml}^{-1}\right)$ and X-Gal (5-bromo-4-chloro3-indolyl $\beta$-D-galactoside) $\left(7 \mu \mathrm{g} \mathrm{ml}^{-1}\right)$ following overnight incubation at $37^{\circ} \mathrm{C}$ (Maniatis et al., 1982). Small-scale plasmid preparations were done according to Holmes \& Quigley (1981) and the insertions confirmed by agarose gel electrophoresis. 
Table 1. Source, serotype and mating type of $C$. neoformans isolates

\begin{tabular}{lccl}
\multicolumn{1}{c}{ Strain } & Serotype & $\begin{array}{c}\text { Mating } \\
\text { type }\end{array}$ & \\
$\begin{array}{l}\text { var. neoformans } \\
\text { NIH-68 }\end{array}$ & A & $?$ & CSF, Missouri \\
NIH-288 & A & $\alpha$ & CSF, Delaware \\
NIH-355 & A & $\alpha$ & Unknown, Minnesota \\
NIH-371 & A & $\alpha$ & Cuckoo dropping, Thailand \\
NIH-386 & A & $\alpha$ & Urine, Iowa \\
NIH-12 & D & $\alpha$ & Abscess, Georgia \\
NIH-52 & D & $?$ & CSF, Maryland \\
NIH-424 & D & $\alpha$ & Pigeon nest, Denmark \\
NIH-433 & D & a & Pigeon nest, Denmark \\
B3501 & D & $\alpha$ & Progeny of the cross NIH-12 $\times$ NIH-433 \\
var. gattii & & & \\
NIH-179 & B & $\alpha$ & Patient, California \\
NIH-184 & B & $\alpha$ & Patient, California \\
NIH-409 & B & $\alpha$ & Cat, California \\
NIH-444 & B & $\alpha$ & Sputum, Washington \\
NIH-3939 & B & $\alpha$ & CSF, Africa \\
NIH-18 & C & $\alpha$ & Dr E. E. Evans, California \\
NIH-34 & C & $\alpha$ & CSF, New Jersey \\
NIH-191 & C & a & CSF, California \\
NIH-401 & C & $?$ & Patient, Oklahoma \\
NIH-403 & C & $?$ & Lung, Oklahoma \\
& & $*$ CSF, cerebrospinal fluid. \\
& & &
\end{tabular}

Southern blot analysis of cloned mtDNA fragments. Plasmids containing the mtDNA fragments were labelled by nick-translation (BRL kit) with ${ }^{32}$ P-deoxycytidine triphosphate (Amersham), and purified by G-50 Sephadex (Pharmacia) spin columns. Total DNA extracted from the various isolates was digested with either $\mathrm{Sal}$ I or $\mathrm{XbaI}$ (depending on the insertion site of the vector used in cloning), and electrophoresed on $0.8 \%$ agarose gels. The DNA from the gels was transferred to nitrocellulose filters (BA85, Schleicher and Schuell) according to the method of Southern (1975). After pre-hybridization for $4-6 \mathrm{~h}$ at $68^{\circ} \mathrm{C}$, the filters were hybridized for $12-16 \mathrm{~h}$ at $68^{\circ} \mathrm{C}$ in the presence of the heat-denatured probe (Maniatis et al., 1982). The filters were washed twice in $100 \mathrm{ml}$ solution $\mathrm{A}$ $(0.3 \mathrm{M}-\mathrm{NaCl} ; 0.06 \mathrm{M}-\mathrm{Tris} / \mathrm{HCl}, \mathrm{pH} 8 ; 0.002 \mathrm{M}-\mathrm{EDTA})$ at room temperature, twice in $100 \mathrm{ml}$ solution $\mathrm{B}$ (solution $\mathrm{A}+1 \% \mathrm{SDS})$ at $68{ }^{\circ} \mathrm{C}$, and finally in $100 \mathrm{ml}$ solution $\mathrm{C}(10 \%$ solution $\mathrm{A})$ at room temperature. All washes were performed in plastic processing pouches (American Bionetics) with continuous agitation. Autoradiography was done by exposing the filters to Kodak XAR-5 X-ray film in cassettes lined with LIGHTNING-PLUs intensifier screens (Dupont).

Hybridizations of the cytochrome oxidase gene fragments STA (EcoRI-HindIII) and STB (BamHI-HindIII) from $S$. cerevisiae to EcoRI-digested mtDNA from several $C$. neoformans isolates of the four serotypes were also done as described above.

\section{RESULTS}

\section{Isolation of $m t D N A$}

mtDNA was readily resolved from nuclear DNA by ultracentrifugation in $\mathrm{CsCl}$ gradients in the presence of bisbenzimide (Fig. 1). The greater intensity of fluorescence observed for the chromosomal DNA band predictably reffected the quantitative differences of the respective DNAs. Among gradients involving isolates of the variety gattii (serotypes B and C), a third minor band located between the mitochondrial and the chromosomal DNA bands was routinely observed (Fig. 1; see Discussion).

\section{Restriction fragment analysis}

Tremendous heterogeneity was observed in the mtDNA restriction patterns from the isolates of $C$. neoformans, regardless of the endonuclease used. Based on the number of mtDNA fragments generated following digestion by several endonucleases, the size of the mitochondrial genome was estimated to range between 40 and $50 \mathrm{~kb}$. Within each serotype (except serotype B), 

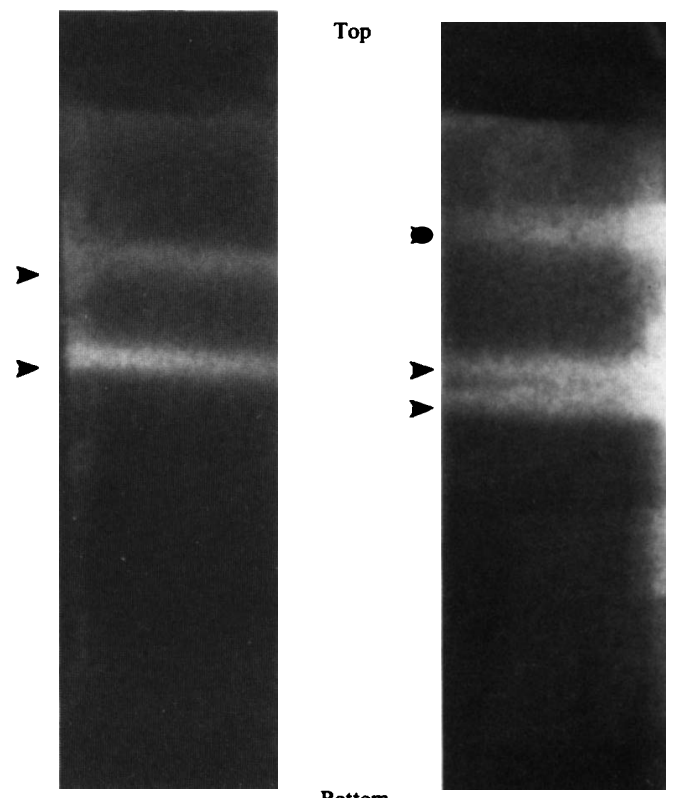

Fig. 1. Ultraviolet fluorescence photograph of bisbenzimide/CsCl gradients of total cellular DNA from an isolate of the variety neoformans (left) and the variety gattii (right), following ultracentrifugation. The DNA bands are arrowed.

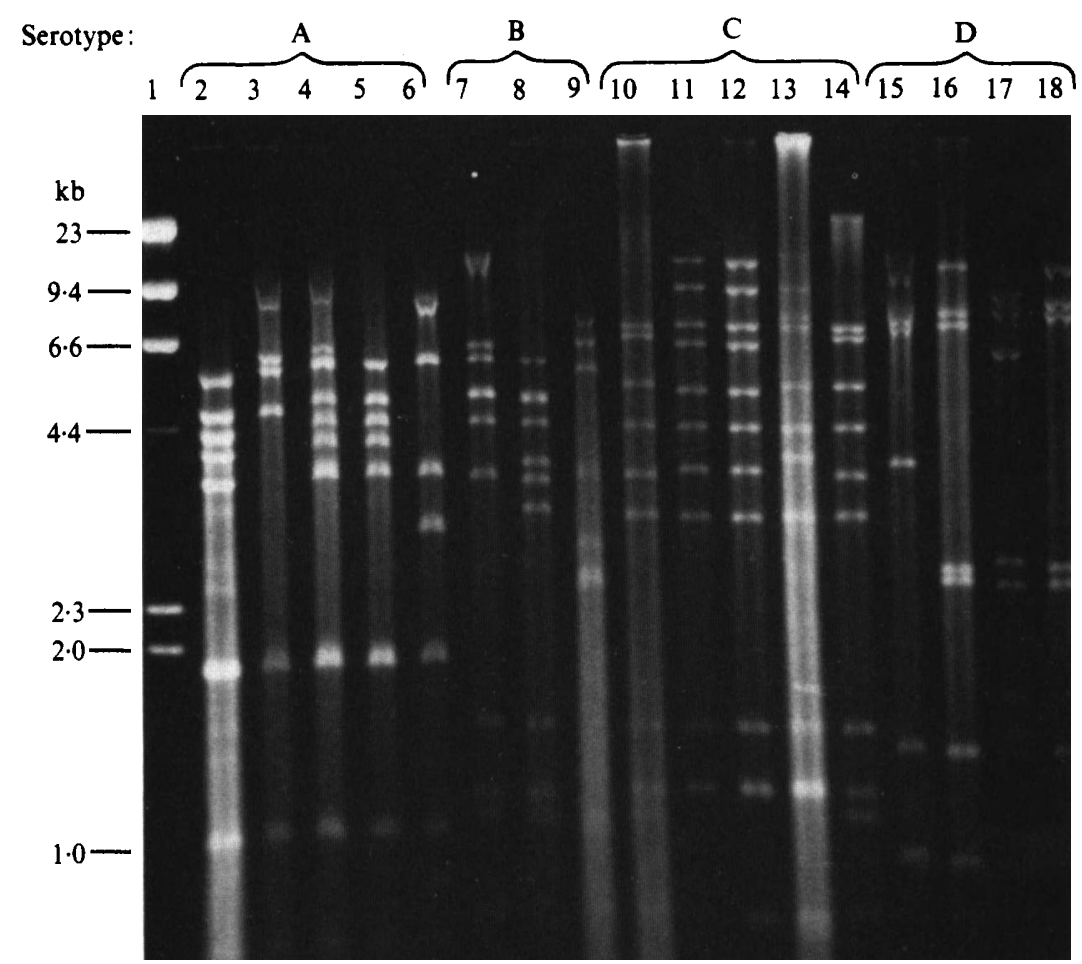

Fig. 2. Restriction fragments generated following digestion of mtDNA with EcoRI. Serotype A : lane 2, NIH-68; 3, NIH-271 ; 4, NIH-288; 5, NIH-371 ; 6, NIH-386. Serotype B : lane 7, NIH-184; 8, NIH-409; 9, NIH-444. Serotype C: lane 10, NIH-18; 11, NIH-34; 12, NIH-191; 13, NIH-298; 14, NIH-401. Serotype D: lane 15, NIH-12; 16, NIH-52; 17, NIH-424; 18, NIH-433. Lane $1, \lambda$ DNA digested with $H$ HindIII. 


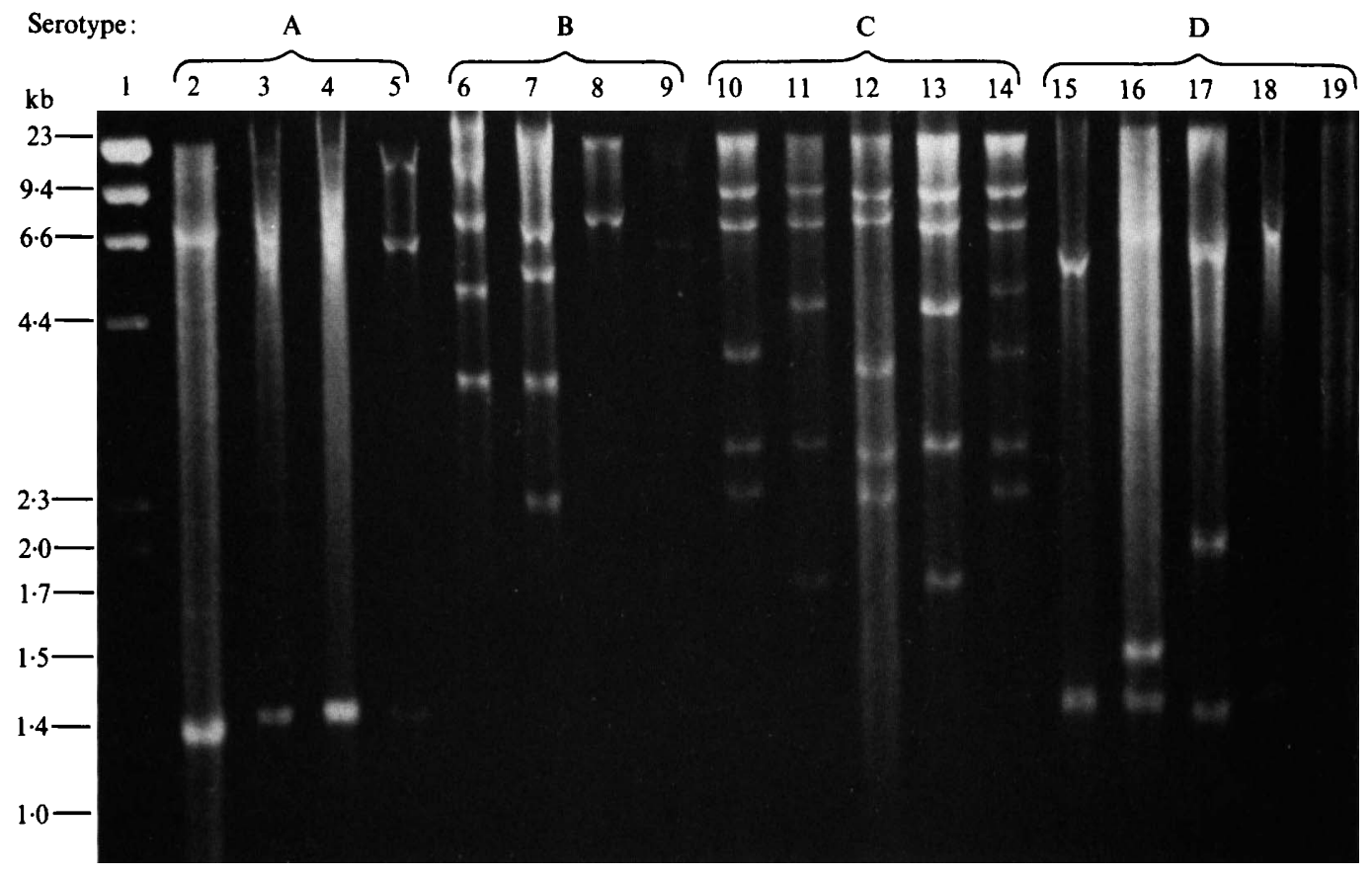

Fig. 3. Restriction fragments generated following digestion of mtDNA with SalI. Serotype A : lane 2, NIH-68; 3, NIH-288; 4, NIH-371 ; 5, NIH-386. Serotype B: lane 6, NIH-179; 7, NIH-184; 8, NIH-444; 9, NIH-3939. Serotype C: lane 10, NIH-18; 11, NIH-34; 12, NIH-191; 13, NIH-298; 14, NIH-401. Serotype D: lane 15, NIH-12; 16 , NIH-52; 17 , NIH-424; 18, NIH-433; 19, NIH-3501. Lane 1, $\lambda$ DNA digested with HindIII.

some isolates displayed similar restriction patterns when digested with either Sal I, EcoRI or $X b a$ I. Among these were NIH-68 and NIH-371 within serotype A, NIH-34 and NIH-191 within serotype C, and NIH-52, NIH-433 and B-3501 within serotype D (Figs 2-4). The restriction patterns among isolates of serotype $B$ were the most variable, regardless of the endonuclease used, and no two isolates exhibited identical restriction patterns. No restriction pattern similarity was observed between isolates of different serotypes or varieties of $C$. neoformans. Certain fragments, however, with some of the endonucleases used, were consistently seen only within the isolates of a particular serotype. Serotype-specific EcoRI restriction fragments included: three $(1.85,1.2$ and $0.7 \mathrm{~kb})$ among isolates of serotype $A$; three $(8.5,4.4$ and $3.1 \mathrm{~kb})$ among isolates of serotype $C$; and two $(1.5$ and $1.0 \mathrm{~kb}$ ) among isolates of serotype $D$ (Fig. 2). In the restriction patterns generated by $X b a \mathrm{I}$, the serotype-specific fragments included: one $(1.0 \mathrm{~kb})$ among isolates of serotype $\mathrm{A}$; one $(3.0 \mathrm{~kb})$ among isolates of serotype $\mathrm{C}$; and three $(2.7$, 2.0 and $1.2 \mathrm{~kb}$ ) among isolates of serotype D (Fig. 4). Similarly, three Sall fragments $(9,4$ and $2.5 \mathrm{~kb}$ ) were serotype-specific among isolates of serotype C (Fig. 3).

Some mtDNA fragments were only observed in the patterns of isolates within a certain

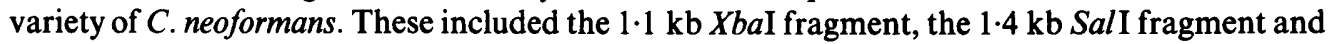
the $0.7 \mathrm{~kb}$ EcoRI fragment among isolates of the variety neoformans, and the $1.5 \mathrm{~kb}, 1.3 \mathrm{~kb}$ and $0.8 \mathrm{~kb}$ EcoRI fragments among the isolates of the variety gattii (Figs 2-4).

\section{Hybridization analysis}

Most of the ${ }^{32} \mathrm{P}$-labelled probes, each containing a different mtDNA fragment, hybridized to restriction fragments of different sizes within an isolate or among isolates of different serotypes (not shown). Some cloned fragments consistently hybridized to a specific fragment within isolates of a certain serotype and/or variety. The $1 \cdot 1 \mathrm{~kb}$ Xbal fragment of NIH-68 (serotype A, 


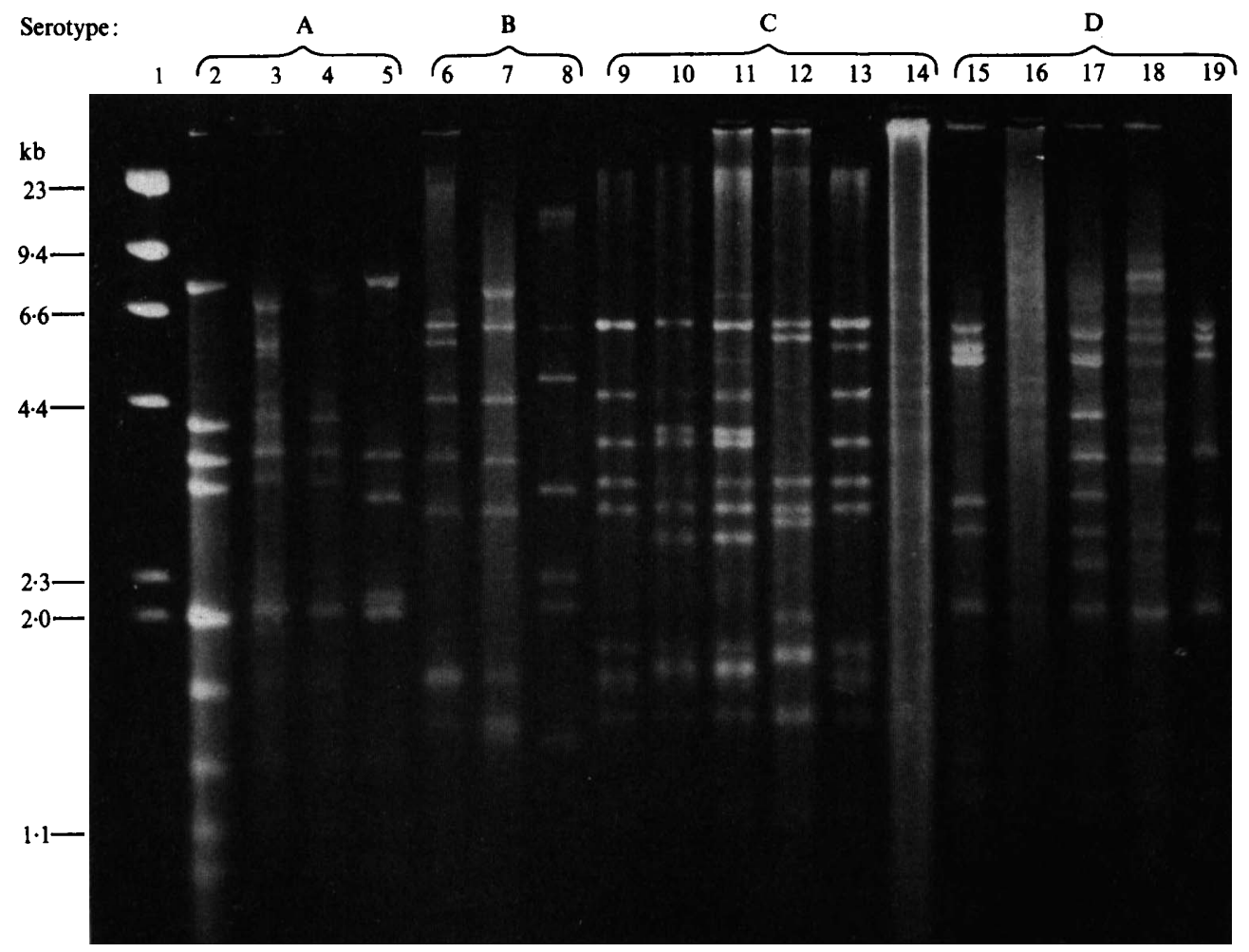

Fig. 4. Restriction fragments generated following digestion of mtDNA with $X b a I$. Serotype A: lane 2, NIH-68; 3, NIH-288; 4, NIH-371 ; 5, NIH-386. Serotype B: lane 6, NIH-179; 7, NIH-184; 8, NIH-444. Serotype C: lane 9, NIH-18; 10, NIH-34; 11, NIH-191; 12, NIH-298; 13, NIH-401; 14, NIH-403. Serotype D: lane 15, NIH-12; 16, NIH-52; 17, NIH-424; 18, NIH-433; 19, NIH-3501. Lane 1, $\lambda$ DNA digested with HindIII.

variety neoformans) was specific for isolates of only the variety neoformans (serotypes A and D) (Fig. 5). The $1.7 \mathrm{~kb} \mathrm{SalI}$ fragment of NIH-191 (serotype C, variety gattii), on the other hand, hybridized to a fragment in each of the isolates studied (Fig. 6). Among the five isolates of serotype C studied, this $1.7 \mathrm{~kb}$ probe hybridized to a $1.7 \mathrm{~kb}$ fragment in two isolates (NIH-34 and NIH-298) and to a $2.3 \mathrm{~kb}$ fragment in the other three isolates (NIH-18, NIH-191 and NIH401 ). This $1.7 \mathrm{~kb} \mathrm{SalI}$ fragment hybridized to only the $1.4 \mathrm{~kb} \mathrm{Sal}$ I fragment in all the isolates of the variety neoformans (serotypes $\mathrm{A}$ and $\mathrm{D}$ ) but detected homology to a different-sized fragment in each of the serotype B isolates analysed.

Hybridization of the EcoRI-HindIII (STA) fragment of the cytochrome oxidase gene from $S$. cerevisiae detected homology to one or two fragments in all isolates of $C$. neoformans studied (Fig. 7). Seven distinct patterns of homology were observed. Strong homology to a $4.5 \mathrm{~kb}$ fragment was seen only among isolates of the variety gattii (serotypes B and C). Two patterns were specific among isolates of serotype $C$ (lanes 10-14). A specific pattern of homology was also observed among certain isolates of the neoformans variety (lanes 3, 4, 15-17). Hybridization with the BamHI-HindIII (STB) fragment of the cytochrome oxidase gene did not detect homology to a fragment in any of the isolates studied. 


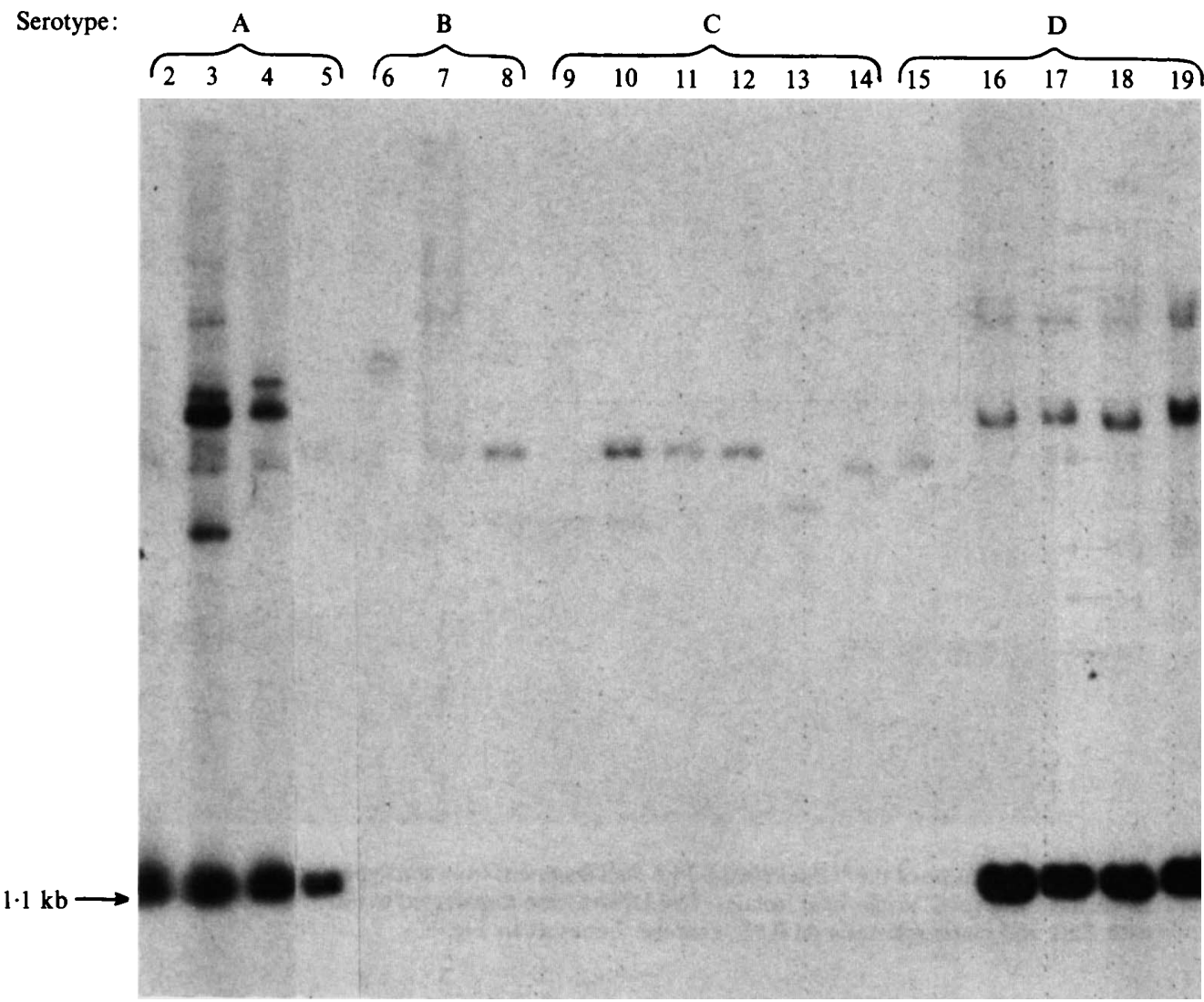

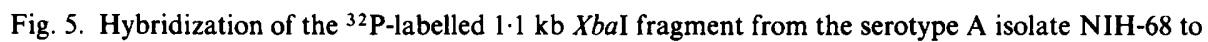
total DNA from several $C$. neoformans isolates. The DNAs were transferred to nitrocellulose after digestion with $\mathrm{XbaI}$ and electrophoresis on $0.8 \%$ agarose. Lanes as in Fig. 4.

\section{DISCUSSION}

mtDNA restriction patterns of $C$. neoformans isolates from the four serotypes were analysed to determine the correlation, if any, between the restriction fragment patterns and the serotype or varietal status of an isolate. The resolution and subsequent separation of mtDNA from nuclear DNA was facilitated by the affinity of bisbenzimide to bind to A-T-rich sequences, thereby altering the buoyant density of the mtDNA. Among isolates of the variety gattii, a third minor band was observed. A band at this location has, in previous studies, been shown to represent ribosomal DNA (Hudspeth et al., 1980). Our observation is consistent with previously reported differences in $\mathrm{G}+\mathrm{C}$ content between isolates of the variety gattii $(56-57.3 \mathrm{~mol} \%)$, and those of the variety neoformans (53-56 mol\%) (Aulakh et al., 1981). The higher $\mathrm{G}+\mathrm{C}$ composition of chromosomal DNA among isolates of the variety gattii causes the chromosomal band to shift downward, exposing the otherwise superimposed ribosomal DNA band.

Analysis of restriction fragments generated by different endonucleases showed extensive heterogeneity among the isolates regardless of their serotype or varietal status. In contast to observations in Histoplasma capsulatum (Vincent et al., 1986), no distinct classes were observed in the sets of restriction patterns. There were, however, similarities among isolates of the same serotype as well as among isolates of the same variety. The presence of similar-sized fragments among isolates of the same serotype or variety, regardless of the endonuclease used, indicates some conservation of the enzyme recognition sequences. 


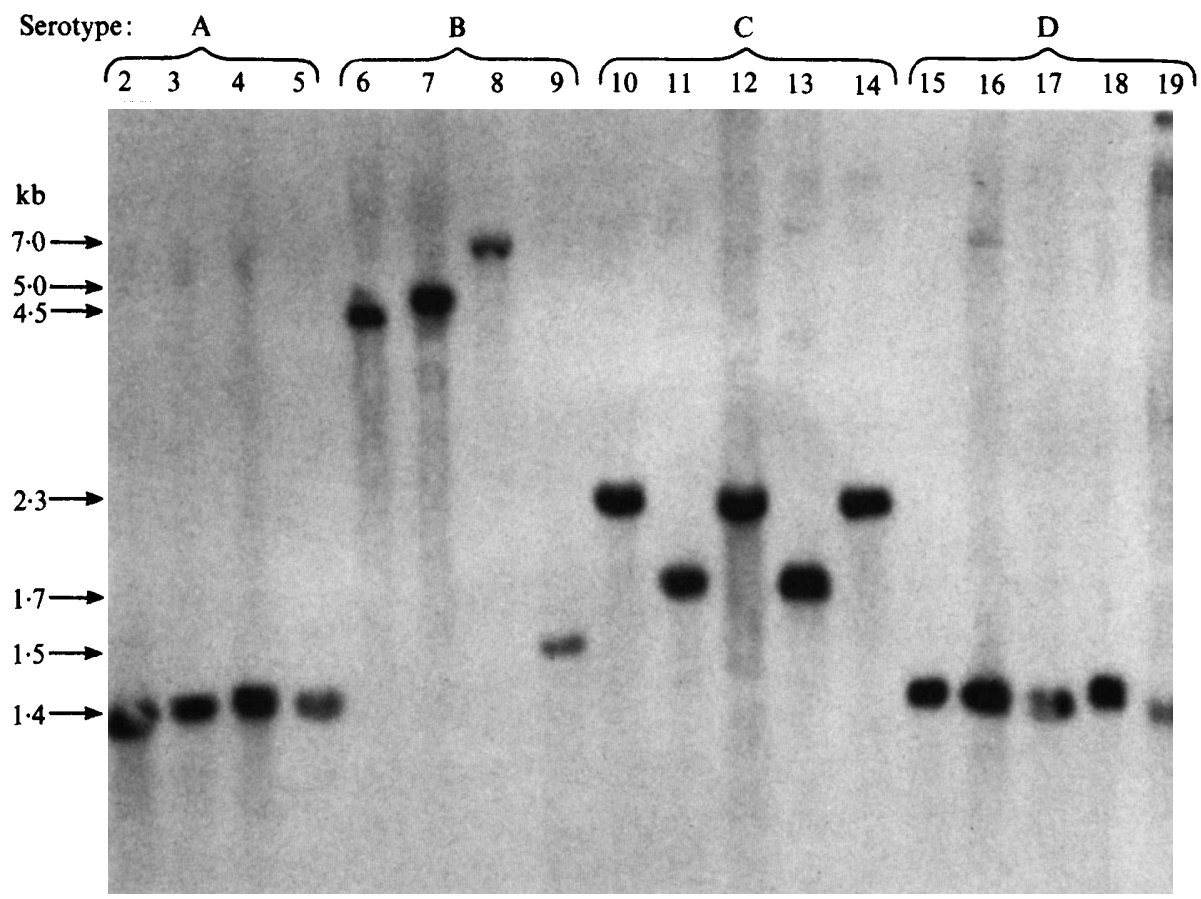

Fig. 6. Hybridization of the ${ }^{32} \mathrm{P}$-labelled $1.7 \mathrm{~kb}$ Sal I fragment from serotype C isolate $\mathrm{NIH}-191$ to total DNA from several $C$. neoformans isolates. The DNAs were transferred to nitrocellulose after digestion with $\mathrm{SalI}$ and electrophoresis on $0.8 \%$ agarose. Lanes as in Fig. 3.

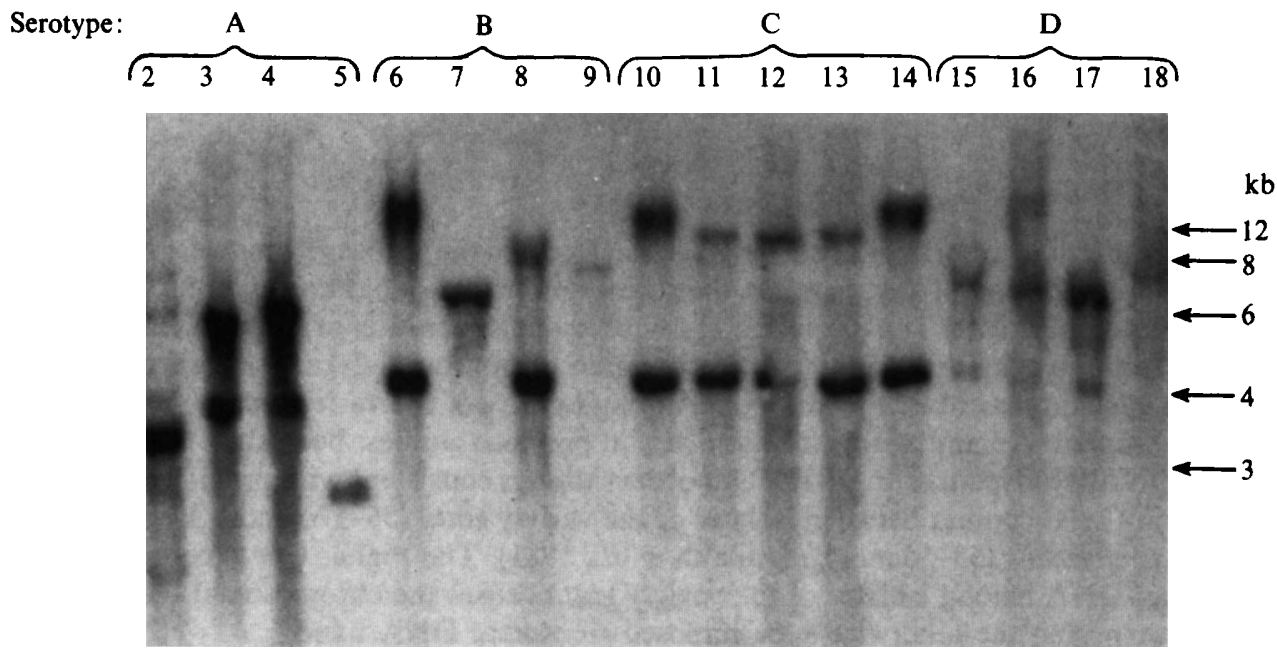

Fig. 7. Hybridization of the ${ }^{32} \mathrm{P}$-labelled STA (EcoRI-HindIII) fragment of the cytochrome oxidase gene from $S$. cerevisiae to $m t D N A$ of several $C$. neoformans isolates. The mtDNAs were transferred to nitrocellulose after digestion with EcoRI and electrophoresis on $0.8 \%$ agarose. Serotype A : lane 2, NIH68 ; 3, NIH-288; 4, NIH-355; 5, NIH-386. Serotype B: lane 6, NIH-179; 7, NIH-184; 8, NIH-444; 9, NIH-3939. Serotype C: lane 10, NIH-18; 11, NIH-34; 12, NIH-191; 13, NIH-298; 14, NIH-401. Serotype D: lane 15, NIH-12; 16, NIH-52; 17, NIH-424; 18, NIH-433. 
To determine whether these similar-sized mtDNA fragments represent homologous sequences, restriction fragments of representative isolates of each serotype were cloned into the $E$. coli vector pUC8 and used as probes against total DNA digests of each of the isolates. The observation of a single zone of homology, corresponding to the insert fragment in the probe, suggests a lack of significant homology to any sequence in chromosomal DNA. The results of the hybridizations varied depending upon the fragment used in the probe. Some fragments exhibited homology in every isolate probed (not shown) while others revealed hybridization patterns specific to isolates of a certain serotype or variety of the species. Hybridizations with specific cloned fragments illustrated both the observed restriction site polymorphism and restriction site conservation within and among isolates of different serotypes and/or varieties. The $1.7 \mathrm{~kb}$ Sal I fragment from the serotype C isolate NIH-191 hybridized to a fragment of different size in each of the serotype $B$ isolates, while hybridizing to only two different-sized fragments $(1.7$ or $2.3 \mathrm{~kb})$ among the isolates of serotype $\mathrm{C}$. On the other hand, this clone detected homology to only a $1.4 \mathrm{~kb}$ fragment in the isolates of the variety neoformans (serotypes A and D). Such restriction site conservation is further demonstrated by the hybridization patterns of a

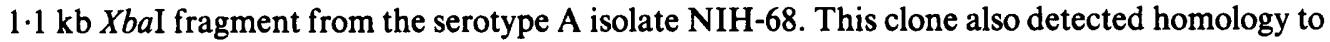
only a single $1.1 \mathrm{~kb} \mathrm{XbaI}$ fragment in each of the variety neoformans isolates analysed. Since the enzymes used recognize 6 bp sequences, the observed polymorphism may well be the result of alterations in the primary nucleotide sequence via insertions, deletions or mutations.

Evolutionary studies involving restriction fragment analysis assume that variations observed among the patterns reflect differences at the nucleotide sequence level. Hybridizations with the STA fragment of the cytochrome oxidase gene from $S$. cerevisiae revealed the conserved nature of the sequences since it detected homology to mtDNA fragments in each of the isolates studied. This fragment exhibited homology to one or more different-sized fragments among the various isolates, further demonstrating the polymorphism in the mtDNA restriction patterns of $C$. neoformans. The patterns of hybridization revealed specificities in keeping with the serotype and varietal status of the respective isolates. These results support the current taxonomic treatment accorded the varieties of $C$. neoformans (Kwon-Chung, 1983).

Current methods to differentiate the two varieties of $C$. neoformans utilize biochemical and antigenic properties of the isolates. These methods have sometimes proved ambiguous, especially among isolates from clinical environments under the influence of antifungal agents (St Germain et al., 1988). The hybridization patterns we observed with various mtDNA clones may serve as an effective tool for determining the varietal status of such isolates.

The degree of change indicated by the observed polymorphism suggests the presence of functionally irrelevant stretches of DNA, given the conserved nature of the genes in the mitochondrial genome. The size of the mitochondrial genome in $C$. neoformans, based on the restriction analysis, was estimated to be between 40 and $50 \mathrm{~kb}$. This size is twice that of the extremely conserved mammalian mtDNA (15-20 kb), half the size of $S$. cerevisiae mtDNA (70$80 \mathrm{~kb}$ ), which is known to have large numbers of introns and exons (Borst \& Flavell, 1976), and 5-10 kb larger than that of Candida albicans ( $41 \mathrm{~kb}$ ), which shows considerably less polymorphism among different isolates (Willis et al., 1985).

Rapid evolution of mtDNA is evidenced by the rather high intra-specific sequence divergence that has been found by restriction analysis of various mammalian mtDNAs (Bonitz et al., 1980). This raises the question of the extent, within a species, to which these nucleotide replacements are actually expressed as phenotypic changes in gene products and the extent to which they may be silent. Comparisons between two coding regions within the mammalian mitochondrial genome (Castora et al., 1980) suggest that a high proportion of the evolutionary base changes are silent. However, comparisons between the evolutionary base changes and resulting amino acid replacements within the yeast and human cytochrome oxidase subunit II genes (Fox, 1979) show an equal divergence of genes and of the polypeptides. It remains unclear exactly how this type of rapid evolution relates to mtDNA evolution. Hauswirth \& Laipis (1982) suggest an amplification model, in which genes undergo tandem duplications, and test for mitochondrial fitness while simultaneously diluting the unrepaired damage at each generation. 
High levels of intraspecific variation suggest a mechanism which may exist to fix rare but functionally significant changes in the mitochondrial genomes. It is possible that the phenotypic characteristics of the two varieties of $C$. neoformans are associated with such alteration.

\section{REFERENCES}

Aulakh, H. S., Straus, S. E. \& Kwon-Chung, K. J. (1981). Genetic relatedness of Filobasidiella neoformans (Cryptococcus neoformans) and Filobasidiella bacillispora (Cryptococcus bacillisporus) as determined by deoxyribonucleic acid base composition and sequence homology studies. International Journal of Systematic Bacteriology 31, 97-103.

Bonitz, S. G., Coruzzi, G., Thalenfeld, B. E. \& TZagoloff, A. (1980). Assembly of the mitochondrial membrane system. Journal of Biological Chemistry 255, 11929-11941.

Borst, P. \& Flavell, R. A. (1976). Properties of mitochondrial DNAs. In Handbook of Biochemistry and Molecular Biology: Nucleic Acids, vol. 2, p. 363. Edited by G. E. Fasman. Cleveland, Ohio: CRC Press.

CASTORA, F. J., ARnheim, N. \& Simpson, M. V. (1980). Mitochondrial DNA polymorphism: evidence that variants detected by restriction enzymes differ in nucleotide sequence rather than methylation. Proceedings of the National Academy of Sciences of the United States of America 71, 6415-6419.

Fox, T. D. (1979). Five TGA 'stop' codons occur within the translated sequence of the yeast mitochondrial gene for cytochrome $c$ oxidase subunit II. Proceedings of the National Academy of Sciences of the United States of America 76, 6534-6538.

GrAY, M. W. (1982). Mitochondrial genome diversity and the evolution of mitochondrial DNA. Canadian Journal of Biochemistry 60, 157-171.

HauswirTh, W. W. \& LaIPIS, P. J. (1982). Mitochondrial DNA polymorphism in a maternal lineage of Holstein cows. Proceedings of the National Academy of Sciences of the United States of America 79, 4686-4690.

Holmes, D. S. \& Quigley, M. A. (1981). A rapid boiling method for the preparation of bacterial plasmids. Analytical Biochemistry 114, 193.

Hudspeth, M. S., Shumard, D. S., Tatti, K. M. \& Grossman, L. I. (1980). Rapid purification of yeast mitochondrial DNA in high yield. Biochimica et biophysica acta 610, 221-228.

KwON-CHUNG, K. J. (1983). Current taxonomic status of Cryptococcus neoformans. Japanese Journal of Medical Mycology 24, 310-313.
KWON-ChUNG, K. J. \& BENNETT, J. E. (1984). Epidemiologic differences between the two varieties of Cryptococcus neoformans. American Journal of Epidemiology 120, 123-130.

Kwon-Chung, K. J., Polacheck, I. \& Bennett, J. E. (1982). An improved diagnostic medium for separation of Cryptococcus neoformans var. neoformans and Cryptococcus neoformans var. gattii. Journal of Clinical Microbiology 15, 535-537.

Maniatis, T., Fritsch, E. F. \& Sambrook, J. (1982). Molecular Cloning, a Laboratory Manual. Cold Spring Harbor, NY: Cold Spring Harbor Laboratory.

Polacheck, I. \& Lebens, G. A. (1989). Electrophoretic karyotype of the pathogenic yeast Cryptococcus neoformans. Journal of General Microbiology 135, 65-71.

Rhodes, J. C. \& Kwon-Chung, K. J. (1985). Production and regeneration of protoplasts from Cryptococcus. Sabouraudia 23, 77-80.

SOUTHERN, E. (1975). Detection of specific sequences among DNA fragments separated by gel electrophoresis. Journal of Molecular Biology 98, 503.

St Germain, G., Noel, G. \& Kwon-Chung, K. J. (1988). Cryptococcus neoformans var. gattii. European Journal of Clinical Microbiology and Infectious Diseases 4, 587-588.

Vincent, R. D., Goewart, R., Goldman, W. E., Kobayashi, G. S., LAMbowitz, A. M. \& MEdoff, G. (1986). Classification of Histoplasma capsulatum isolates by restriction fragment polymorphism. Journal of Bacteriology 165, 813-818.

Williamson, H. \& FenNell, D. J. (1975). The use of fluorescent DNA-binding agent for detecting and separating yeast mitochondrial DNA. Methods in Cell Biology 12, 335-351.

Willis, J. W. Troutman, W. B. \& Riggsby, W. S. (1985). Circular mitochondrial genome of Candida albicans contains a large inverted duplication. Journal of Bacteriology 164, 7-13.

WILSON, D. E., BENNETT, J. E. \& BAILEY, J. W. (1968). Serologic grouping of Cryptococcus neoformans. Proceedings of the Society of Experimental Biology and Medicine 127, 820-823. 